\title{
PENGEMBANGAN BUDIDAYA SORGUM TANAMAN PANGAN ALTERNATIF PADA DAERAH BAYANGAN HUJAN DI NAGARI RAMBATAN KABUPATEN LIMA PULUH KOTA
}

\author{
Eka Candra Lina ${ }^{1)}$ dan Wenny Surya Murtius ${ }^{2)}$ \\ 1) Fakultas Pertanian Universitas Andalas \\ 2) Fakultas Teknologi Pertanian Universitas Andalas \\ Email: eka_candra@agr.unand.ac.id
}

\begin{abstract}
ABSTRAK
Sorgum merupakan tanaman yang adaptif, dapat tumbuh optimal pada lahan kering dan masam, dan tahan terhadap kondisi marjinal (kekeringan, salinitas dan lahan masam). Tanaman ini memiliki manfaat sebagai sumber karbohidrat pengganti beras dan dapat diolah menjadi produk turunan lainnya. Sejauh ini masyarakat mengkonsumsi bulir sorgum yang diolah secara tradisional antara lain di buat bubur atau di kukus dan langsung dinikmati. Selain itu, dengan pengolahan yang baik dapat menjadikan sorgum sebagai pangan fungsional kesehatan potensial. Tujuan kegiatan ini adalah untuk meningkatkan perekonomian masyarakat sekitar dengan memberikan pengetahuan dan informasi terkait pengolahan dan budidaya sorgum. Kegiatan dilaksanakan dalam bentuk penyuluhan, pelatihan, dan pendampingan. Di akhir program terjadi transfer teknologi yang dapat meningkatkan pengetahuan dan pendapatan masyarakat di Nagari Rambatan. Dari hasil kegiatan diperoleh bahwa Jorong Pabalutan dan Dusun Ladang Laweh berada di Nagari Rambatan Kecamatan Rambatan Kabupaten Tanah Datar, Sumatera Barat. Nagari Rambatan mempunyai 1.550 kepala keluarga yang mayoritas petani padi di sawah, menyadap karet, dan lain-lain. Luas lahan persawahan di Nagari Rambatan sekitar 27.442 Ha. Kondisi umum yang dihadapi petani adalah masalah pengairan, petani hanya bertanam padi di sawah dua kali dalam setahun bahkan hanya sekali dalam setahun. Hal ini disebabkan karena Rambatan termasuk daerah bayangan hujan. Salah satu upaya untuk mengisi kekosongan lahan saat musim kemarau adalah dengan melakukan budidaya tanaman sorgum. Selanjutnya hasil survei terhadap kelompok tani Sepakat dan kelompok tani Kuta Bali menunjukkan keinginan yang kuat untuk mendapatkan transfer pengetahuan dan teknologi yang terkait dengan budidaya sorgum yang baik dan benar.
\end{abstract}

Kata Kunci : bisnis, budidaya, kelompok tani, Rambatan, sorgum

\section{Development of Alternative Food Plant Sorgum Cultivation at Rain Shadows In Nagari Rambatan, Lima Puluh Kota District}

\begin{abstract}
Sorghum is an adaptive plant, can grow optimally on dry and acid soil and is resistant to marginal conditions (drought, salinity, and acid soils). This plant has benefits from carbohydrates to replace rice and can be processed into other derivative products. People consume sorghum that is processed traditionally, among others, made porridge or steamed and enjoyed immediately. Also, with proper processing, it can make sorghum potential health functional food. This activity aims to improve the economy of the surrounding community by providing knowledge and information related to sorghum processing and cultivation. Activities were carried out in the form of counseling, training, and mentoring. At the end of the program, a technology transfer can increase people's knowledge and income in Nagari Rambat. The activity results found that Jorong Pabalutan and Dusun Ladang Laweh were located in Nagari Rambat, Rambat District, Tanah Datar Regency, West Sumatra. Nagari Rambat has 1,550 families, the majority of whom are rice farmers in the fields, tapping rubber. The area of rice fields in Nagari Rambat is around 27,442 hectares. The general condition faced by farmers is irrigation problems; farmers only plant rice in the fields twice a year, even only once a year. This is because the propagation is a rain shadow area. One of the efforts to fill the void of land during the dry season is by
\end{abstract}


cultivating sorghum. Furthermore, the Sepakat farmer groups' survey results and the Kuta Bali farmer groups show a strong desire to obtain a transfer of knowledge and technology related to proper and correct sorghum cultivation.

Keywords: business, cultivation, farmer groups, Rambat, sorghum

\section{PENDAHULUAN}

Jorong Pabalutan dan Dusun Ladang Laweh merupakan salah satu jorong yang berada di Nagari Rambatan Kecamatan Rambatan Kabupaten Tanah Datar Provinsi Sumatera Barat, Kecamatan Rambatan itu sendiri adalah satu dari 8 Kecamatan di Kabupaten Tanah Datar yang terletak di $00^{\circ} 17^{\prime \prime}$ LS - 00 39" LS dan $100^{\circ} 19^{\prime}$ BT - $100^{\circ} 51^{\prime}$ BT. Nagari Rambatan mempunyai penduduk 33.117 dengan 1.550 kepala keluarga yang mayoritasnya adalah petani. Tingkat pendidikan masyarakat rendah dengan jumlah pengangguran mencapai 3.709 orang.

Pada umumnya, penggunaan lahan di Nagari Padang Laweh didominasi oleh lahan untuk perkebunan (karet, kopi, kulit manis, coklat, pisang, kelapa, pinang dan lain-lain) atau kebun campur seluas $1.517 \mathrm{Ha}$. Penggunaan lahan untuk persawahan seluas $777 \mathrm{Ha}$, dengan Tegalan seluas $155 \mathrm{Ha}$, permukiman seluas $185 \mathrm{Ha}$, keadaan sawah tadah hujan dan yang di airi dengan irigasi hanya $10 \mathrm{Ha}$. Area perikanan darat seluas $15 \mathrm{Ha}$, lahan hutan seluas 1.759,8 Ha, lahan kritis seluas 518,20 Ha dan sisanya adalah lahan yang belum diusahakan yang terdiri dari tanah tandus dan padang ilalang dan seluas 30 Ha. Masyarakat pedesaan mayoritas bergerak di sektor pertanian, saat ini masih banyak daerah yang belum optimal dalam budidaya pertanian terkendala oleh ketersediaan air akibat minimnya sistem irigasi. Petani sawah tadah hujan yang mencapai luas $767 \mathrm{Ha}$ hanya melakukan tanam padi dua kali bahkan satu kali dalam setahun. Hal ini menyebabkan masyarakat sangat tergantung pada hasil perkebunan yang didominasi oleh tanaman karet. Saat ini tanaman karet mencapai harga terendah sehingga sangat berdampak pada perekonomian masyarakat petani (Dinas Perkebunan Kabupaten Sijunjung, 2009)

Upaya yang dapat dilakukan untuk mengatasi persoalan tersebut adalah dengan menciptakan lapangan pekerjaan yang dapat menyerap tenaga kerja dan meningkatkan perekonomian masyarakat. Salah satunya adalah dengan menggali dan mengembangkan sektor pertanian yang menjadi mata pencaharian utama penduduk. Sebanyak 27.442 Ha lahan di Nagari Rambatan merupakan lahan persawahan. Petani hanya bertanam padi di sawah dua kali dalam setahun bahkan hanya sekali dalam setahun. Memasuki musim kemarau petani menganggur karena ketersediaan air tidak mencukupi untuk bercocok tanam padi. Menanam sorgum merupakan alternatif pilihan karena hanya tanaman sorgum yang dapat tumbuh optimal pada lahan kering dan masam, memiliki daya adaptasi yang luas, dan tahan terhadap kondisi marjinal (kekeringan, salinitas dan lahan masam).

Tanaman sorgum memiliki manfaat sebagai sumber karbohidrat pengganti beras, bersifat gluten free, rendah gula, dan kaya serat. Pengolahan yang baik akan dapat menjadikan sorgum sebagai pangan fungsional kesehatan karena memiliki kandungan gluten dan indeks glikemik (IG) yang lebih rendah sehingga aman di 
konsumsi oleh penderita diabetes (Susilowati., et.al 2009). Dicko et.al (2005) mengatakan bahwa sorgum mengandung senyawa fenolik yang memiliki aktivitas antioksidan, antitumor, dan dapat menghambat perkembangan kanker. Produknya yang bersifat Gluten Free sangat cocok di konsumsi oleh anak autis. Hasil penelitian Zakaria et al. (2009) meneliti mengenai produk berbasis tepung sorgum memperlihatkan bahwa Indeks stimulan untuk sorgum adalah 1,714 . Hal ini menandakan bahwa ekstrak glukan dari sorgum mempunyai aktivitas imunomodulator dan dapat mencegah kanker.

Berbagai manfaat tersebut memberi peluang bagi petani untuk menghasilkan produk pangan alternatif di musim kemarau dan memiliki nilai jual dengan mengandung manfaat yang banyak bagi konsumen. Cara budidaya sorgum yang benar perlu disosialisasikan kepada petani setempat agar petani dapat melakukan proses budidaya dan penanganan saat panen dengan baik. Selain itu upaya pengolahan sorgum menjadi produk turunan juga perlu disosialisasikan kepada masyarakat agar mampu meningkatkan perekonomian dengan memproduksi produk turunan sorgum yang bernilai jual.

\section{METODOLOGI}

Situasi dan kondisi yang dihadapi oleh petani di Rambatan, Batu Sangkar dalam menghadapi musim kemarau dan terhentinya proses bercocok tanam karena kekurangan air perlu segera dicarikan solusinya. Peluang menanam tanaman pangan alternatif yang lebih adaptif terhadap kondisi tersebut sangat terbuka lebar, salah satunya adalah budidaya sorgum. Pengenalan tanaman sorgum dan cara bercocok tanam yang benar perlu diberikan kepada petani secara menyeluruh. Transfer pengetahuan dan teknologi tepat guna tentang budidaya sorgum akan meningkatkan pengetahuan petani, meningkatkan hasil produksi sorgum sekaligus meningkatkan pendapatan petani dan diharapkan dapat meningkatkan perekonomian petani di Rambatan, Batu Sangkar.

Adapun metode yang akan dilakukan dalam kegiatan ini adalah berupa kegiatan penyuluhan dan pendampingan petani terkait tentang pemberian ilmu pengetahuan dan informasi mengenai teknik budidaya sorgum yang baik dan benar. Serta pendampingan mengenai teknologi panen dan pascapanen serta pengolahan menjadi produk turunan yang bernilai jual.

\section{Penyuluhan dan Diskusi}

Tahap pertama yang dilakukan adalah penyuluhan oleh Tim kegiatan Universitas Andalas kepada kelompok tani mitra Sepakat dan Kuta Bali. Tim PKM dan kelompok tani mitra akan berkumpul di aula pertemuan Kebun percobaan Balai Pengkajian Teknologi Pertanian (BPTP). Adapun penyuluhan yang akan diberikan adalah tentang Acara yang dilaksanakan adalah proses pendekatan dengan petani melalui penyuluhan dari tim kegiatan Universitas Andalas yang dimoderatori oleh Wenny Surya Murtius A.Pt., MP. Dalam kegiatan penyuluhan, materi terkait disampaikan oleh pemateri yang berasal dari TIM kegiatan yaitu Dr. Eka Candra Lina, SP. MSi. IPM. Adapun materi penyuluhan yang akan diberikan adalah tentang : 
a. Pengenalan Tanaman Sorgum

b. Budidaya Sorgum dan Pengendalian Hama Ramah Lingkungan

c. Panen dan Pasca Panen Sorgum

Penyuluhan dilakukan terhadap kelompok tani Sepakat dan Kuta Bali bersama TIM kegiatan yang terdiri atas satu dosen dengan bidang kajian dari Hama dan Penyakit Tanaman dan 1 dosen dari bidang kajian Teknologi Pertanian. Proses sosialisasi meliputi kegiatan pemberian materi oleh narasumber kepada kelompok tani dengan metode penyuluhan dan diskusi terkait topik atau kegiatan budidaya tanaman pangan sorgum sebagai alternatif tanaman budidaya di musim kemarau.

Diskusi terpusat kepada kelompok tani, setiap anggota kelompok tani diberikan kesempatan untuk menanyakan kendala atau permasalahan yang ditemui dalam proses atau kegiatan budidaya pertanian. Setiap pertanyaan yang diajukan akan dijawab oleh masing-masing dosen berdasarkan bidang kajian atau keahlian. Diharapkan dengan adanya sesi diskusi dapat membantu menjawab permasalahan petani dalam budidaya sorgum.

\section{Pelatihan Budidaya Sorgum}

Setelah dilakukan penyuluhan dan diskusi maka dilakukan praktek budidaya sorgum. Praktek meliputi Pengolahan tanah yang terdiri dari: Tanah dibajak satu atau dua kali, kemudian digaru dan diratakan dan dibuat saluran air. Tanah yang telah siap ditanami berada pada kondisi bersih dari gulma karena fase pertumbuhan sorgum agak lambat kira-kira 3 - 4 minggu sehingga pada awal pertumbuhan tersebut kurang mampu bersaing terhadap gulma.

Selanjutnya adalah penanaman, pada proses ini sangat diperhatikan populasi tanaman. Pada umumnya tanaman sorgum ditanam sebagai tanaman seta pada tanaman pokok padi gogo, kedelai atau tanaman palawija lainnya. Bila ditanam secara monokultur populasi tanaman per/hektar sekitar 100.000 - 150.000 tanaman. Jarak tanam yang dianjurkan adalah $75 \times 25 \mathrm{~cm}$ atau $75 \times 20 \mathrm{~cm}$ dengan masing-masing dua tanaman per lubang. Pada saat yang bersamaan juga dilakukan penanaman di pinggir areal sebagai tanaman sulam. Tanaman membutuhkan perawatan ekstra pada 2 minggu pertama.

Pemeliharaan sorgum meliputi pemupukan yang diberikan pada saat tanam sebanyak 2 ton per hektar, selanjutnya pada saat tanaman berumur 1 bulan dilakukan pemupukan ulang dengan NPK yang disebarkan di larikan $7 \mathrm{~cm}$ dari tanaman.

Pemeliharaan dan pembubunan merupakan faktor penting bagi pertumbuhan tanaman secara optimal. Pembubunan dilakukan saat tanaman berumur 15 hari untuk memperkokoh batang. Sampai umur dua minggu sorgum harus benar-benar terawat karena belum dapat bersaing dengan gulma.

Pengendalian hama dan penyakit juga di perlukan terutama serangan jamur, bakteri, dan serangga. Monitoring perlu dilakukan secara berkala agar metode pengendalian yang tepat dapat diaplikasikan. Penggunaan pestisida merupakan alternatif pengendalian terakhir yang digunakan. 
Panen dan penyimpanan perlu memperhatikan beberapa hal bulir sorgum matang sempurna setelah 3 bulan 10 hari sejak hari tanam atau lebih kurang 45 hari setelah bakal biji terbentuk. Panen dilakukan dengan memangkas tangkai malai $75 \mathrm{~cm}$ dari pangkal malai, selanjutnya dikeringkan hingga kadar air mencapai 10\% sd 12\%. Selanjutnya biji sorgum dirontokkan menggunakan alat atau dipukul2. Bulir sorgum dipisahkan dari kotoran kemudian di masukkan ke dalam karung dan disimpan di penyimpanan yang dialasi panel hingga saat di gunakan.

Pengolahan sorgum dapat dilakukan dengan Teknik penyosohan hingga menjadi beras, kemudian dijadikan tepung, atau langsung dikonsumsi setelah dirontokkan.

\section{HASIL DAN PEMBAHASAN}

Permasalahan yang dihadapi oleh masyarakat di Nagari Rambatan, bahwa masyarakat tidak mengetahui atau mengenal tanaman sorgum sebelumnya. Oleh sebab itu perlu dilakukan pengenalan tanaman sorgum terlebih dahulu kepada masyarakat di Nagari Rambatan. Suhaemi (2019) mengatakan bahwa sebelum melakukan sosialisasi terhadap masyarakat disuatu Nagari sangat di perlukan upaya pengenalan terhadap produk atau tanaman yang akan disosialisasikan. Karena banyak penduduk sekitar yang masih belum mengetahui tentang pentingnya sosialisasi produk atau tanaman tersebut.

Pengenalan sorgum disampaikan oleh pemateri dengan membawa contoh sorgum. Sorgum (Sorghum bicolor L.) bukan tanaman asli Indonesia, tapi berasal dari sungai Niger di Afrika. Domestika sorgum dari Etiopia ke Mesir dilaporkan telah terjadi sekitar 3000 tahun sebelum masehi. Di Indonesia sorgum telah lama dikenal oleh petani khususnya di Jawa, NTB dan NTT. Di Jawa dengan nama Cantel dan sering ditanam sebagai tanaman sela atau tumpang sari. Budidaya tanaman sorgum di Indonesia masih sangat terbatas bahkan belum begitu populer di masyarakat. padahal sorgum memiliki potensi besar untuk dibudidayakan dan dikembangkan secara komersial karena memiliki daya adaptasi yang luas, produktivitas tinggi, tahan terhadap hama dan penyakit tanaman serta lebih tahan terhadap kondisi marjinal (kekeringan, salinitas dan lahan masam).

Hasil yang diperoleh dari kegiatan berupa peningkatan pengetahuan petani terkait tanaman adaptif yang cocok di tanam di daerah mereka. Terjadi diskusi antara pemateri dengan kelompok tani mengenai tanaman sorgum. Sebelum penyuluhan dan pelatihan dilaksanakan tim melakukan penanaman sorgum di daerah rambatan. Pada saat sosialisasi tanaman sorgum telah berbuah sehingga petani dapat melihat langsung tanaman sorgum dengan varietas numbu dan merah (Gambar 1). Tanaman sorgum di tanam di antara tanaman jeruk yang belum terlalu besar. Petani juga dapat melihat bahwa tanaman sorgum dapat menjadi tanaman sela sebelum tanaman utama masuk ke fase generatif. Menurut Sahuri (2017) Sorgum sebagai tanaman sela pada tanaman karet memberi dampak positif terhadap pertumbuhan karet belum menghasilkan (TBM).

Suasana sosialisasi dan Penyuluhan terhadap kelompok tani Sepakat dan Kuta Bali yang telah dilakukan di kebun percobaan Balai Pengkajian Teknologi Pertanian, Rambatan, Kabupaten Agam pada Gambar 2. 


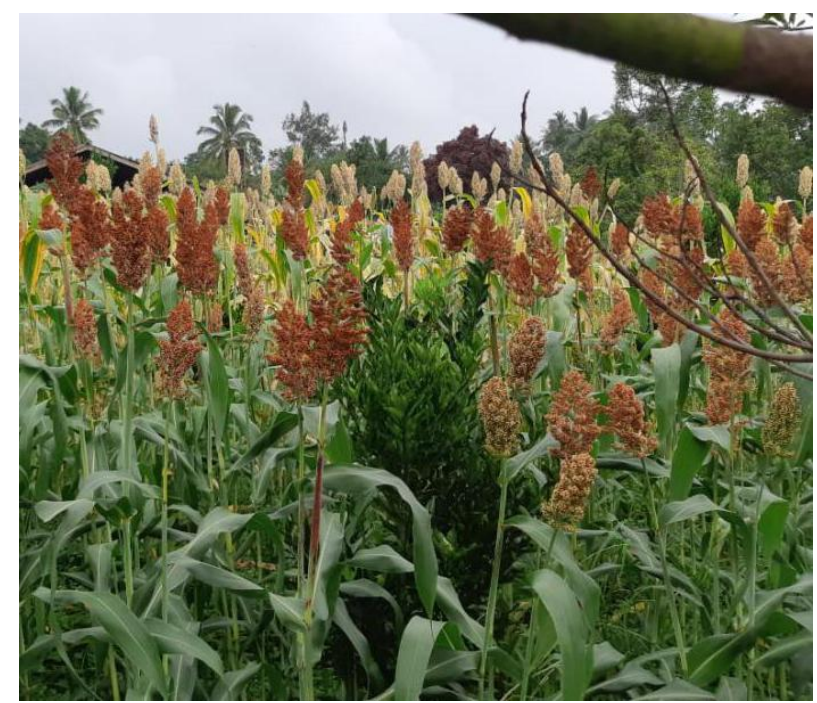

Gambar 1. Sorgum Varietas Numbu dan Merah di Rambatan

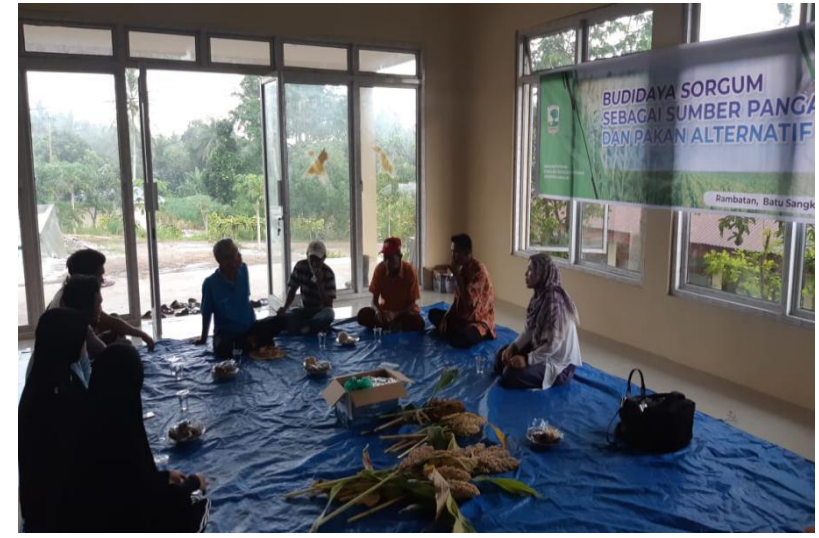

Gambar 2. Sosialisasi dan Penyuluhan Budidaya Sorgum pada Lahan Kering

Anggota kelompok sangat antusias untuk mengetahui Teknik budidaya sorgum dengan detail. Salah satu pertanyaan yang memancing diskusi panjang adalah pengolahan hasil panen dan pemasaran hasil panen. Tim kegiatan menjelaskan secara singkat pengolahan hasil panen untuk konsumsi sendiri. Sedangkan untuk tujuan komersil, kelompok tani akan dibekali lagi dengan materi lanjutan.

Selain sebagai pangan alternatif, hijauan sorgum sisa panen dapat dibuat silase untuk pakan ternak atau diberikan secara langsung sebagai hijauan. Tanaman sorgum diketahui memiliki kandungan gizi yang sangat baik bagi ternak ruminansia. Sorgum juga dapat dimanfaatkan sebagai pakan ternak unggas (biji) maupun ternak ruminansia (batang dan daun). Di negara maju, sorgum banyak digunakan sebagai bahan baku industri seperti industri bioetanol, bir, kertas, plastik bio, sirup, pati, dan bermacam makanan olahan (ICRISAT, 1990). Masyarakat di Nagari Rambatan banyak yang tidak mengetahui manfaat dari tanaman sorgum tersebut. Akan tetapi dengan dilakukan nya sosialisasi dan pengenalan terhadap tanaman tersebut, sedikit demi sedikit masyarakat 
di Nagari Rambatan paham dan mengerti akan manfaat tanaman sorgum tersebut.

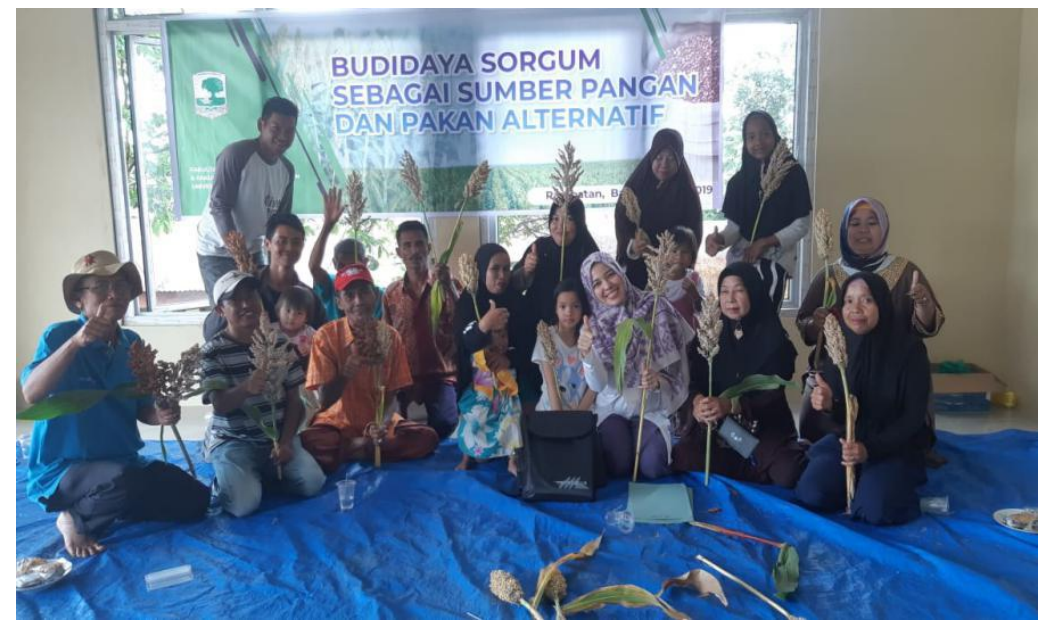

Gambar 3. Tim Kegiatan Unand Melaksanakan Sosialisasi Budidaya Sorgum Yang Baik dan Benar Pada Petani di Rambatan

Budidaya sorgum dapat berintegrasi dengan peternakan dan perikanan, hal ini menjadikan sorgum sebagai tanaman serbaguna. Selain itu dengan budidaya sorgum ada beberapa keuntungan yang di peroleh petani, yaitu sistem ratun, memungkinkan petani hanya mengolah lahan satu kali saja dan panen sebanyak 3 kali. Tanaman sorgum juga membantu pemulihan lahan marjinal menjadi lahan yang subur dan produktif. Tanaman sorgum merupakan salah satu tanaman fitoremediasi, yaitu suatu teknologi baru dengan penggunaan tumbuhan untuk memperbaiki kesuburan tanah yang tercemar baik akibat pekerjaan tambang juga residu dari penggunaan pupuk kimia yang berlebihan. Dengan menanam sorgum maka produktivitas lahan akan meningkat dan juga mendukung upaya pengembangan pertanian berkelanjutan dan peningkatan produksi pangan Indonesia. Selain itu, masyarakat di Nagari Rambatan juga dapat mengelola hasil panen mereka menjadi produk yang bernilai jual dan bergizi sehingga dapat meningkatkan perekonomian masyarakat di Nagari Rambatan.

Manfaat lain yang dapat diperoleh dari kegiatan ini yaitu masyarakat bisa menjadikan produk olahan sorgum menjadi salah satu ciri khas daerah mereka, dan ini tentu akan banyak menguntungkan bagi masyarakat maupun pemerintahan daerah tersebut. Lina (2019), mengatakan bahwa UMKM sangat perlu dibina dan dibimbing dalam pengembangan produk agar produk lokal atau produk daerah dapat bersaing di pasar nasional maupun internasional dengan mengikuti pelatihan-pelatihan dan pendampingan yang dilakukan oleh tim pelaksana kegiatan dengan tujuan agar UMKM mengerti dan memahami pesaing mereka sehingga mereka bisa mencari solusi untuk perkembangan produk mereka sendiri. Sama hal nya dengan masyarakat di Nagari Rambatan, juga sangat di perlukan upaya pelatihan dan pendampingan dalam pengolahan produk turunan sorgum agar masyarakat mampu memproduksi bahan menghasilkan produk dengan trend zaman kini agar tidak kalah saing dengan produk dari daerah-daerah lain. 


\section{KESIMPULAN DAN SARAN}

Luaran yang diperoleh dari kegiatan ini adalah meningkatnya pengetahuan petani mengenai budidaya sorgum. Petani mampu menanam dan mengolah sorgum sebagai tanaman alternatif di musim kemarau. Petani dapat meningkat pendapatannya karena masa paceklik di musim kemarau tetap bisa melakukan pekerjaan bercocok tanam.

\section{UCAPAN TERIMAKASIH}

Penulis mengucapkan terima kasih kepada LPPM Universitas Andalas untuk dukungan atas kegiatan yang telah dilaksanakan. Ucapan terima kasih juga disampaikan kepada kelompok tani Sepakat dan Kuta Bali yang berada nagari Rambatan serta tim teknisi atas bantuan dalam kegiatan ini.

\section{DAFTAR PUSTAKA}

Crisat. 1990. Industrial Utilization of Sorghum. Proceedings of Symposium on the Current Status and Potential of Industrial Uses of Sorghum. 59p.

Dicko, M.H., H. Gruppen, A.S. Traore, W.J.H. van Berkel,and A.G.J. Voragen. 2005. Evaluation of the effect ofgermination on phenolic compounds and antioxidantactivities in sorghum varieties. Journal of Agriculturaland Food Chemistry, 53: 2581-2588.

Lina, Eka Candra., Donard Games., Prima Fithri., Yulianita Leoni. 2019. Inkubasi Produk Unggulan Nagari Sinuruik Kecamatan Talamau Kabupaten Pasaman Barat. Jurnal Hilirisasi IPTEKS, 2:(3a).

Suhaemi, Zasmeli., Syahrial., Ilham Martadona., Devi Dianti. 2019. Aplikasi Teknologi Berbasis Daun Kelor (Moringa oleifera) guna meningkatkan nilai ekonomis lahan. Jurnal Hilirisasi IPTEKS, 2:(3a).

Susilowati, A., Aspiyanto, S. Moemiati, dan Y. Maryati.2009. Pengembangan pangan fungsional berbasissorgum (Sorghum bicolor L.) untuk anti kolesterol.http://www.lipi.go.id/www.cgi?depan. Diakses 1/4/2012.

Zakariah, F.R., R, Tahir, Suismono, Subarna, danWaysima. 2009. Produksi dan pemasaran tepung instan serealia sorgum dan jewawut sebagai panganfungsional antikanker. Lembaga Penelitian dan Pengabdian Masyarakat. IPB. Bogor. 
Jurnal Hilirisasi IPTEKS

Vol. 3 No. 3, September 2020

Website. http://hilirisasi.lppm.unand.ac.id

e-ISSN: 2621-7198

Sahuri. 2017. Uji adaptasi sorgum manis sebagai tanaman sela di antara tanaman karet belum menghasilkan. Jurnal Penelitian Karet, 35(1): 23-38. 